\title{
Placenta-derived exosomes: potential biomarkers of preeclampsia
}

\author{
This article was published in the following Dove Press journal: \\ International Journal of Nanomedicine \\ 31 October 2017 \\ Number of times this article has been viewed
}

\section{Preenan Pillay ${ }^{1,2}$ \\ Kogi Moodley' \\ Jagidesa Moodley ${ }^{3}$ \\ Irene Mackraj ${ }^{3}$}

'Discipline of Human Physiology, Nelson R Mandela School of Medicine, School of Laboratory Medicine and Medical Sciences, University of KwaZulu-Natal, Durban, South Africa; ${ }^{2}$ Pearson Institute of Higher Education, Midrand, South Africa; ${ }^{3}$ Women's Health and HIV Research Group, Nelson R Mandela School of Medicine, School of Laboratory Medicine and Medical Sciences, University of KwaZulu-Natal,

Durban, South Africa
Correspondence: Irene Mackraj Women's Health and HIV Research Group, Nelson R Mandela School of Medicine, School of Laboratory Medicine and Medical Sciences, University of KwaZulu-Natal I University Road, Westville, Durban 400I, South Africa Tel +27 729085646 Fax +27 260707 I Email mackraji@ukzn.ac.za

\begin{abstract}
Preeclampsia remains a leading cause of maternal and fetal mortality, due to ineffective treatment and diagnostic strategies, compounded by the lack of clarity on the etiology of the disorder. Although several clinical and biological markers of preeclampsia have been evaluated, they have proven to be ineffective in providing a definitive diagnosis during the various stages of the disorder. Exosomes have emerged as ideal biomarkers of pathological states, such as cancer, and have more recently gained interest in pregnancy-related complications, due to their role in cellular communication in normal and complicated pregnancies. This occurs as a result of the specific placenta-derived exosomal molecular cargo, which may be involved in normal pregnancy-associated immunological events, such as the maintenance of maternal-fetal tolerance. This review provides perspectives on placenta-derived exosomes as possible biomarkers for the diagnosis/prognosis of preeclampsia. Using keywords, online databases were searched to identify relevant publications to review the potential use of placenta-derived exosomes as biomarkers of preeclampsia.
\end{abstract}

Keywords: placenta-derived exosomes, preeclampsia, biomarkers

\section{Introduction}

Preeclampsia $(\mathrm{PE})$ is a multiorgan systemic hypertensive disorder of pregnancy (HDP) that is a leading cause of maternal and fetal mortality. ${ }^{1-3}$ The exact etiology of $\mathrm{PE}$ is difficult to establish, due to the multifactorial nature of the disorder; however, the general theoretical framework underlying the etiology of PE centers on abnormal placentation due to inadequate spiral-artery remodeling caused by poor trophoblast invasion. ${ }^{4,5}$ Moreover, it is now understood that increased placental oxidative stress is triggered by a predisposing condition, which stimulates the release of microvesicles from the syncytial layer of the placenta. ${ }^{6,7}$ These extracellular vesicles (EVs), termed syncytiotrophoblast microvesicles (STBMs), may bind to monocytes and stimulate the production of proinflammatory cytokines, which results in altered maternal systemic inflammatory response (MSIR) in normal and preeclamptic pregnancies..$^{8-11}$ In addition, ex vivo studies have shown that STBMs have a key role in maternal immunomodulation that results in regulation of T-helper $1\left(T_{h} 1\right) / T_{h} 2$ immunoresponses in normal pregnancy, ${ }^{8}$ and may thus be responsible for the $\mathrm{T}_{\mathrm{h}} 1$ skewness in PE. ${ }^{12}$

It is now recognized that the exact nature and composition of STBMs has yet to be defined with regard to proportion of exosomes, apoptotic bodies, and other vesicles. In light of this, recent literature has indicated that the constituents of STBMs should be classified as EVs and thus be termed STBEVs. ${ }^{13}$ Though prior knowledge of STBEVs indicates that these vesicles in their entirety can be used as circulating STB biopsies, ${ }^{14}$ they cannot be clearly defined as biomarkers of PE, as studies have 
not demonstrated the objective isolation and detection of PE-specific biomarkers. In addition, studies conducted by the Obstetrics and Gynaecology Unit at the University of Oxford have shown that exosomes may be a key constituent of STBMs involved in the pathogenesis of the disorder. ${ }^{7,8,10,12-19}$ These fundamental observations support the potential of placenta-derived exosomes as a biomarker of PE. Therefore, this review aims to evaluate the potential application of exosomes as a biomarker of PE.

\section{Understanding the spectrum of pregnancy-related hypertensive disorders}

HDPs are classified into four groups: 1) PE and eclampsia, 2) chronic hypertension (of any cause), 3) chronic hypertension with superimposed PE, and 4) gestational hypertension. Clinical classification of the types of HDP is based primarily on gestational age, blood pressure, and compounding complications (Figure 1). PE is defined as an HDP that has been characterized extensively in clinical practice, as it is associated with an increased risk of fetal and maternal morbidity and mortality. ${ }^{20}$ Without early-detection strategies, PE is clinically diagnosed as new-onset hypertension with proteinuria, ${ }^{20,21}$ and can be further subcategorized into earlyand late-onset PE. ${ }^{21-24}$ Based on gestational age, early-onset $\mathrm{PE}$ is defined by new-onset hypertension at $<33$ weeks plus
6 days of gestation and late-onset PE defined by new-onset hypertension $>34$ weeks of gestation. ${ }^{22-24}$ However, the severity of PE pregnancies can be differentiated by their clinical manifestations, as outlined by clinical practice guidelines that present the adverse conditions and severe complications of PE according to the end organs affected. ${ }^{25}$

Adverse conditions in $\mathrm{PE}$ are associated with risks that increase the odds of severe maternal and fetal complications, and when exaggerated complications lead to severe (that warrant delivery). ${ }^{25}$ Diagnosis of these complications is primarily based on clinical maternal symptoms and laboratory tests. In addition, gestational hypertension, superimposed PE, and PE can progress to severe PE if one or more severe complications manifest, which thus necessitates improved clinical monitoring-management systems using defined prognostic and diagnostic methods. Thus far, the only known cure of $\mathrm{PE}$ is the early delivery of the fetus and placenta to prevent worsening of disease progression and associated maternal complications, which leads to prematurity and its subsequent complications. ${ }^{25,26}$ All these complications emphasize the need for a biomarker that would enable early diagnosis and development of a treatment method for PE to prevent the inherent distress induced by it.

\section{Biomarkers of PE: the current state}

Biomarkers are universally defined as biochemical alterations that can be objectively detected and quantified in

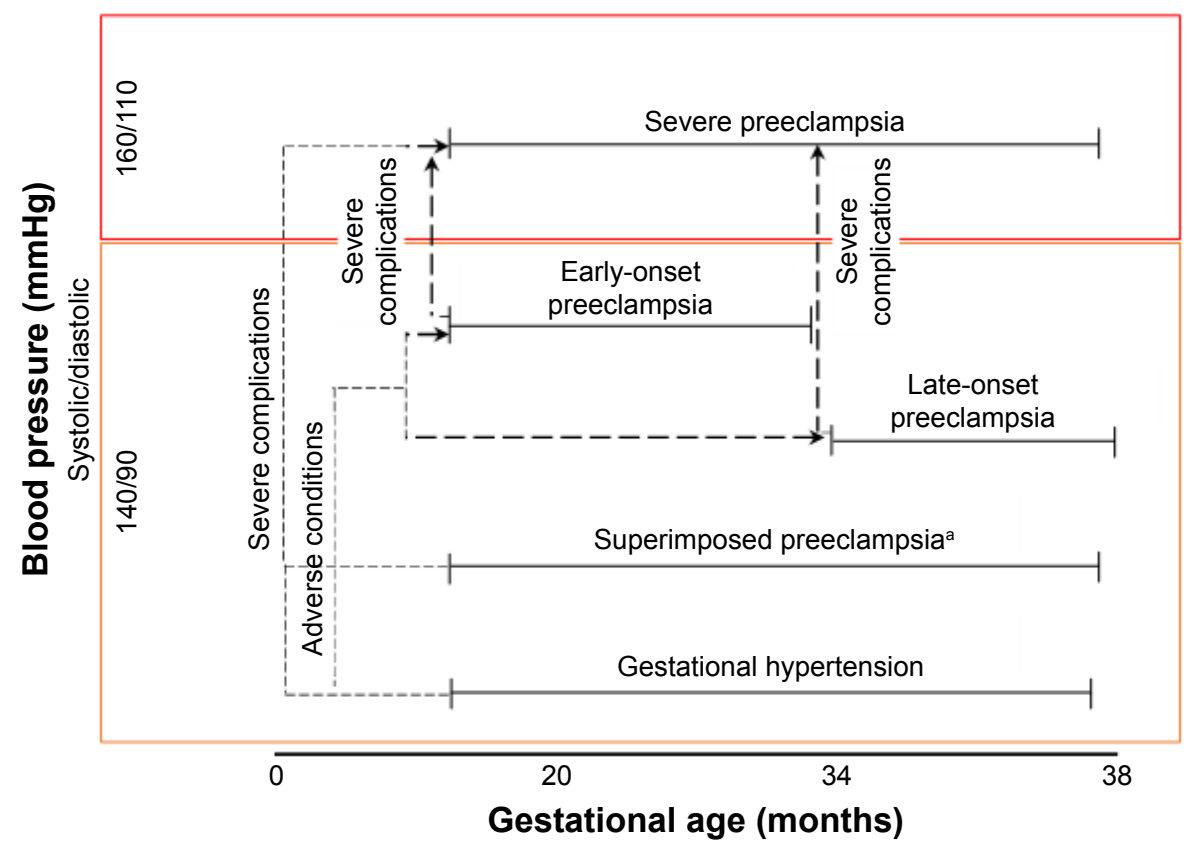

Figure I Classification of hypertensive disorders in pregnancy.

Notes: Hypertensive disorders with preeclampsia subclassified into early- and late-onset preeclampsia. Adverse conditions are defined as conditions that increase the risk of severe complications. Adverse conditions and severe complications are categorized into the organ system affected (ie, central nervous system, cardiorespiratory, hematological, renal, hepatic, and fetoplacental), as described by Magee et al. ${ }^{25}$ aHypertension present either at prepregnancy or that developed at 20 weeks prior to gestation. 
human tissue, cells, or fluids and evaluated as an indicator of normal biological processes, pathogenic processes, or pharmacological responses to therapeutic intervention. ${ }^{27}$ It is thus imperative that these criteria are met when identifying potential biomarkers of PE to develop an efficient clinical test for early diagnosis and differentiation of the severity of PE. However, this is a challenge, due to the complex etiology and pathology of PE.

Clinical markers, such as maternal factors, blood pressure, proteinuria, and uterine-artery Doppler velocimetry remain the most reliable methods in PE monitoring and supportive care of the mother and fetus. However, they cannot be used in the early diagnosis of $\mathrm{PE},{ }^{21,28}$ but may still serve as useful markers when used in combination with other PE biomarkers. Previous studies (Table 1) have shown that combined clinical and biological markers have improved detection rates in overt PE, which could be incorporated into clinical care for early screening and assessment of patientspecific risks of PE. ${ }^{29-31}$ However, the limitation of combined clinical markers and biological markers is the inability of these markers to provide definitive differentiation of the severity of PE and assessment of the PE-disease pathway. Currently, combined biomarkers of PE include cytokines, proteins, angiogenic and antiangiogenic factors that have a fundamental role in the pathogenesis and etiology of PE, as well as other related HDPs. ${ }^{32-34}$

\section{Angiogenic and antiangiogenic factors}

Thus far, antiangiogenic sFlt1 and angiogenic PGF in combination serve as the most promising biomarkers for the diagnosis of PE. ${ }^{35-38}$ This is mainly attributed to the synergistic role of these molecules in the pathogenesis of PE, whereby an altered angiogenic balance induced by sFlt1, inhibits PGF signaling, resulting in vascular endothelial dysfunction, a key feature of PE. ${ }^{32,37-39}$ Although the precise physiologic role of these factors is not fully understood, the elevated circulating levels of sFlt1 and decreased PGF observed in overt PE highlight their combined biomarker potential, ${ }^{33,37,38,40}$ Furthermore, a recent study presented the differential diagnostic potential of the sFlt1:PGF ratio in PE. . $37,38,41,42^{2}$ This ratio proved to be effective in the diagnosis of overt PE in the third trimester of pregnancy, together with differential diagnosis of severe gestational and chronic hypertension at $\geq 34$ weeks' gestation. ${ }^{35,31}$ Regardless of the favorable sensitivity and specificity of the sFlt1:PGF ratio, its clinical usage is restricted as a late-pregnancy diagnostic and management tool for severe or overt HDP. ${ }^{42}$ A case-control multicenter study showed that use of differential cutoffs for the various

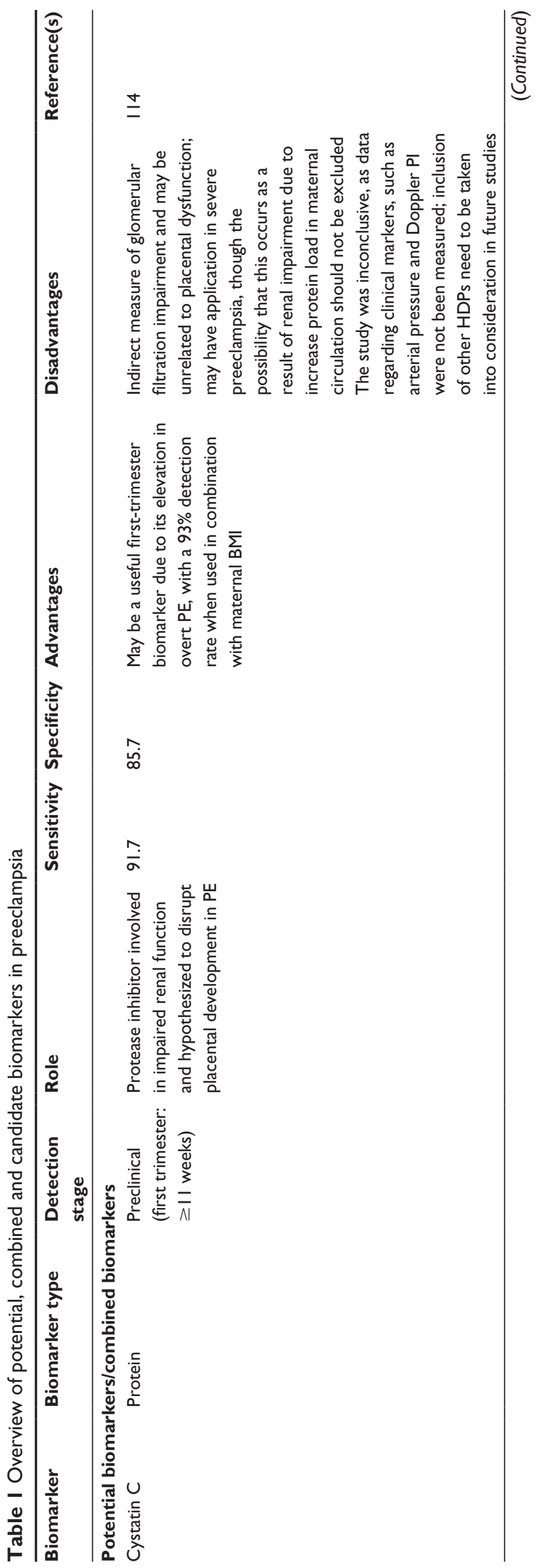




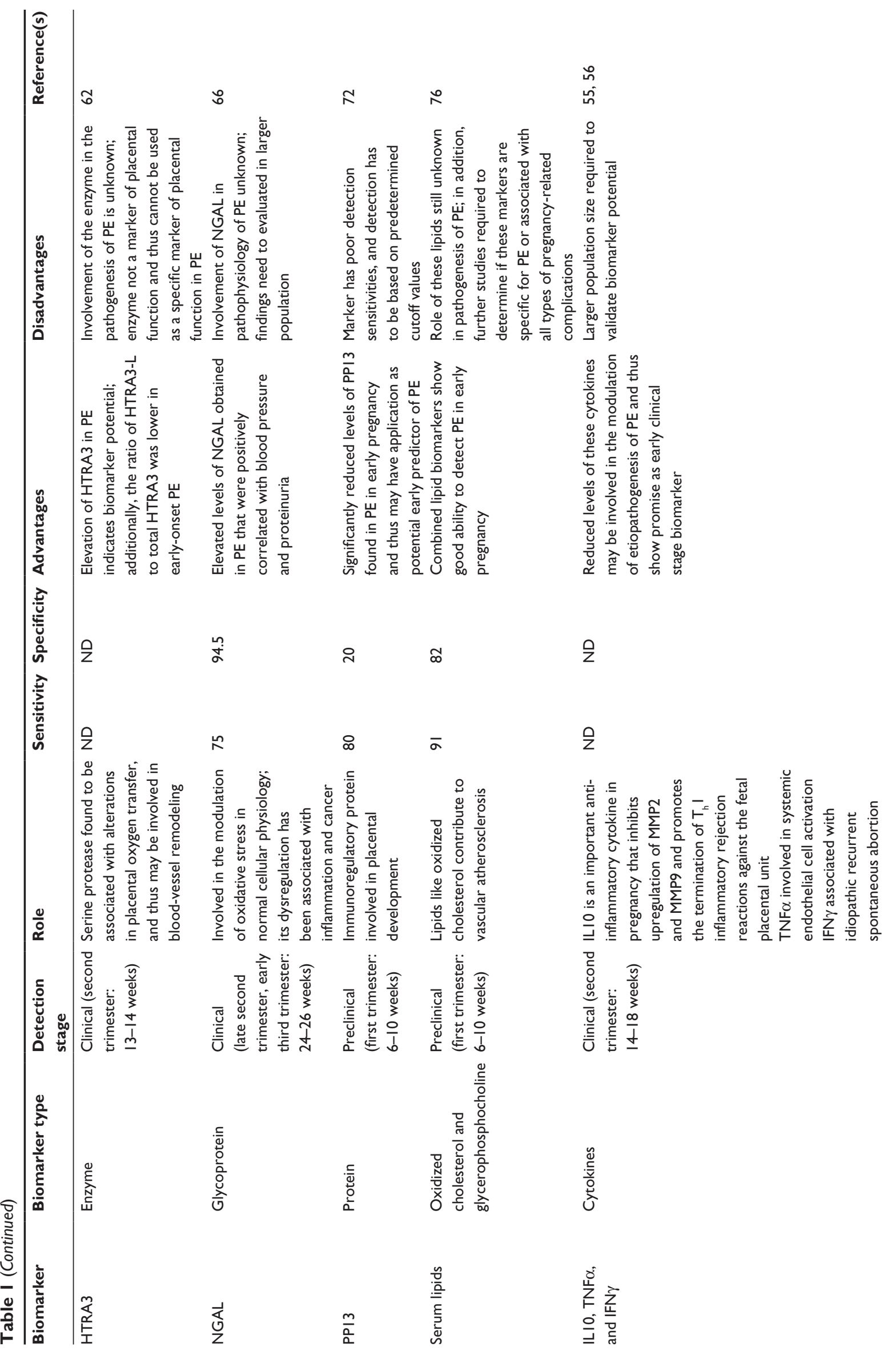


in

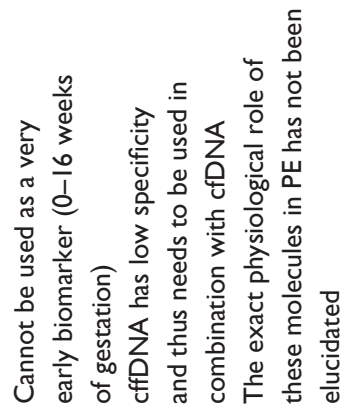

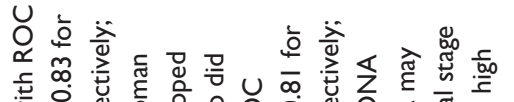

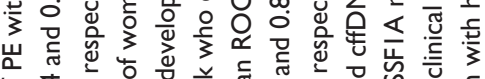

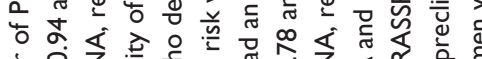

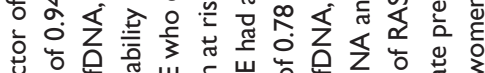

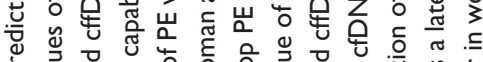

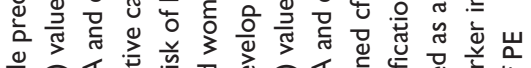

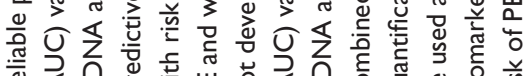

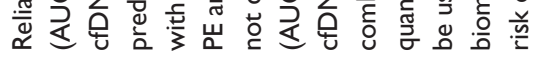

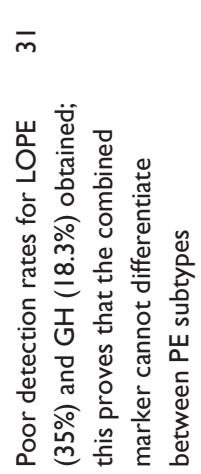

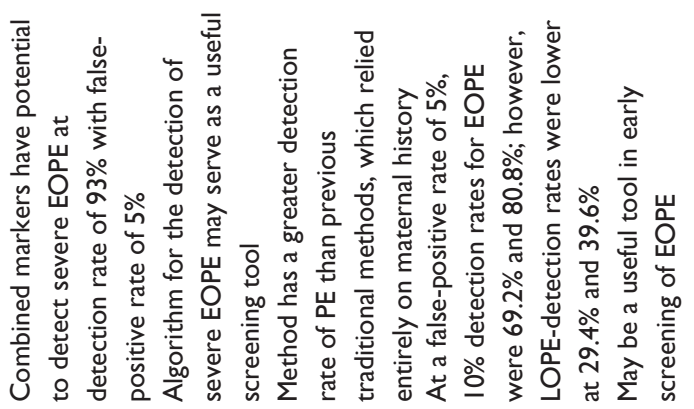

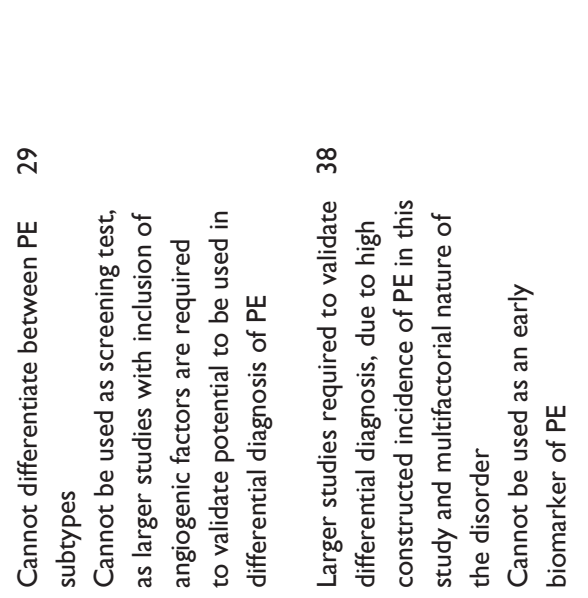

号

१

文

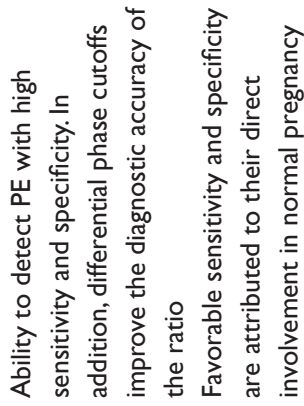

$\stackrel{n}{\alpha} \frac{1}{d}$

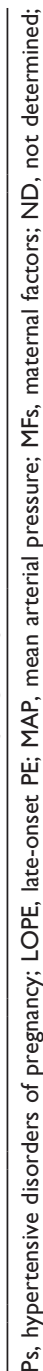
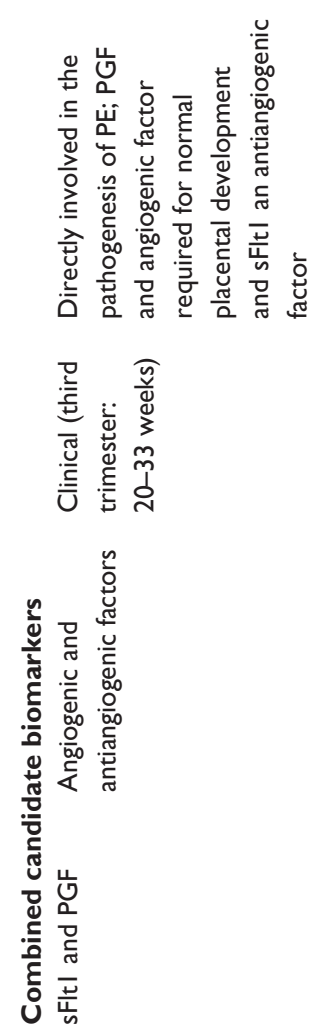

$n$
$\infty$
$\infty$
$\infty$

告

車
२

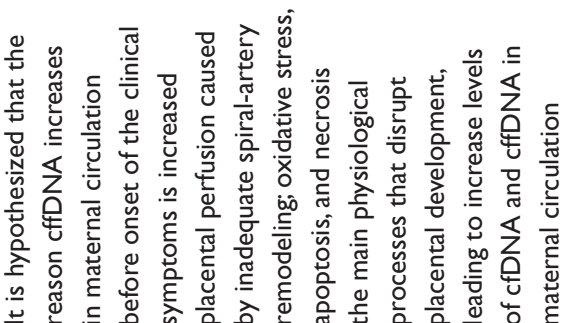

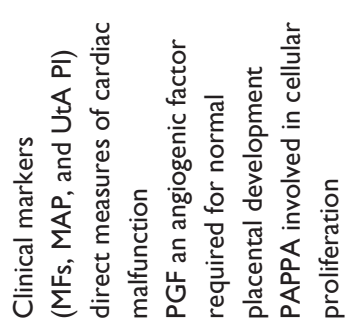
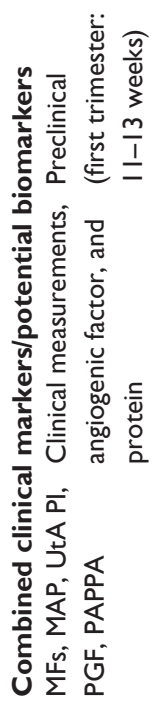

१
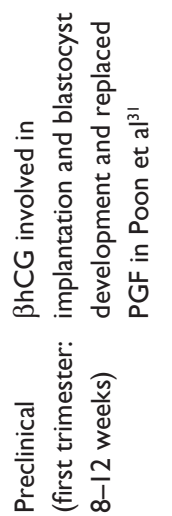

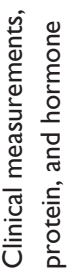

过

ए क्

这离

紋高

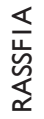


gestational phases enhanced the diagnostic potential of the sFlt1:PGF ratio. ${ }^{38}$ This study, however, did not show falsepositive or false-negative values, due to the high constructed incidence of PE and variability of the disorder. Therefore, validation of the sFlt1:PGF ratio in a clinical setting with a larger, homogeneous population is required. sEng, a key antiangiogenic factor implicated in $\mathrm{PE}$, has been found to be elevated in maternal circulation in the second trimester in PE-predisposed patients. ${ }^{4-45}$ Although sEng values alone or in combination with other pro- and antiangiogenic factors are significantly altered in PE serum, it has proven to be a poor biomarker of the disorder. ${ }^{46}$

\section{Cell-free fetal DNA}

cfDNA and cffDNA are also probable combined biomarkers of PE, mainly due to their sensitivity and specificity in biological fluids. ${ }^{47,48}$ The identification of the methylated RASSF $1 A$ promoter gene, which is elevated in early-PE pregnancies, ${ }^{49-51}$ offers a promising alternative to the quantification of cffDNA, using Y-chromosome-specific sequences. ${ }^{52}$ Notably, high doses of human cffDNA did not induce PE-like symptoms in a murine in vivo model,$^{53}$ reinforcing the notion that the increase in RASSF1A methylation is a consequence rather than a cause of PE. Nevertheless, when used in combination with other markers, cffDNA RASSF1A methylation may have potential in monitoring $\mathrm{PE}$ development in the second trimester. $^{49-51}$

\section{Cytokines}

Cytokines are significantly involved in the pathophysiology of PE, as they are instrumental in the maintenance of the $\mathrm{T}_{\mathrm{h}} 1-\mathrm{T}_{\mathrm{h}} 2$ balance in normal pregnancy. ${ }^{9}$ During normal pregnancy, there is a shift toward $\mathrm{T}_{\mathrm{h}} 2$ immunity that results in the synthesis of IL4, IL5, IL6, and IL10, whereas in PE there is a distinct shift toward $\mathrm{T}_{h} 1$ immunity, resulting in the production of IL2, TNF $\alpha$, and IFN $\gamma .{ }^{54}$ It is this shift toward $\mathrm{T}_{\mathrm{h}} 1$-associated immunity in PE that results in the exaggerated MSIR. Therefore, $\mathrm{T}_{\mathrm{h}} 1$ - and $\mathrm{T}_{\mathrm{h}}$ 2-associated cytokines have gained interest as potential PE biomarkers. Research conducted in patients in the early second trimester of pregnancy has indicated that IL10-, TNF $\alpha$-, and IFN $\gamma$-expression levels were significantly altered in PE during weeks 14-18 of gestation. ${ }^{55-58}$ Therefore, these cytokines in combination may serve as potential early biomarkers of $\mathrm{PE}$ if validated in a larger sample population. In addition, GDF15, a macrophage-inhibiting cytokine possessing cardioprotective and biomarker potential in cardiovascular disease, has been found to be significantly reduced in PE women..$^{59}$ However,
GDF15 cannot be used as a biomarker of PE in the first trimester of pregnancy, as no marked differences between normotensive and PE pregnancies have been observed. Although cytokines may be involved in the pathophysiology of PE, their application as possible biomarkers is questionable, since key cell-mediated factors are involved in their regulation during pregnancy.

\section{High-temperature-requirement A3 enzyme}

HTRA3, a pregnancy-related serine protease expressed by placental extravillous trophoblast cells, may have biomarker potential in the early detection of PE. ${ }^{60}$ It has been found to be associated with altered placental oxygen transfer and bloodvessel remodeling in the first trimester. ${ }^{61}$ Elevated levels of HTRA3 in weeks 13-14 of gestation have been observed in PE-predisposed patients. ${ }^{62}$ Although the potential application of HTRA3 as a biomarker is promising, it has limited application, since factors responsible for altered expression of this enzyme in PE are still unclear. Additionally, this enzyme is not a specific marker of placental function, and thus cannot be used an indicator of placental maladaptation in PE.

\section{Pregnancy-associated plasma protein A}

PAPPA, a more relevant, pregnancy-related protease involved in early placental development, has been found to be dysregulated in intrauterine growth restriction, $\mathrm{PE}$, placental abruption, and premature birth. ${ }^{63}$ PAPPA is responsible for the cleavage of IGFBP4, hence regulating the synthesis of IGF, a key growth factor in the regulation of placental and fetal growth. ${ }^{64}$ Dysregulation of this enzyme may be linked to a variety of pregnancy-related complications associated with generalized placental function. Due to the aspecificity of this enzyme, it cannot be used as a marker of PE, but may have diagnostic application in combination with other clinical measurements and biomarkers. ${ }^{65}$

\section{Neutrophil gelatinase-associated lipocalin}

NGAL, a lipocalin-type glycoprotein involved in iron sequestration normally associated with inflammation, neoplastic transformation, and renal damage, has been found to be linked to PE. ${ }^{66}$ Increased serum NGAL is proportional to the severity of PE in the late second trimester of pregnancy, with sensitivity and specificity of $75 \%$ and $94.5 \%$, respectvely. ${ }^{67}$ However, NGAL is not linked exclusively to placental maladaptation, and its role in PE is unclear. Additionally, maternal serum AFP, in combination with maternal factors, the uterine-artery pulsatility index, and mean arterial pressure, 
has shown potential in the diagnosis of PE in weeks 19-24 of gestation in combination with other biomarkers. ${ }^{68}$

\section{Placental protein}

PP13 has been reported extensively in early placental development, ${ }^{69,70}$ and may be involved in T-cell and macrophage apoptosis, regulation of maternal immunoresponses, and maternal-fetal immunomodulation. ${ }^{70,71}$ Due to its association with early placental development, it may be useful in detecting PE during early pregnancy. ${ }^{72}$ A significantly lower concentration of PP13 in weeks 6-10 of gestation has been found in PE-predisposed patients, which was attributed to impaired trophoblastic regulation and spiral-artery remodeling in PE. ${ }^{72}$ Studies involving PP13 as a biomarker are limited, due to the lack of sample-population homogeneity and poor detection sensitivity; in addition, sensitivity and specificity for detection has to be determined using predefined cutoff values. Interestingly, STBEVs have been shown to be immunopositive for PP13, ${ }^{70}$ suggestive of an immunomodulatory role. Therefore, future studies must evaluate PP13-biomarker potential in association with STBEVs and exosomes.

\section{Syncytiotrophoblast extracellular vesicles}

STBEVs may play a role in maternal-fetal immunoadaptation. ${ }^{73}$ In addition, in vitro research has indicated that PE-derived STBEVs differentially affect immune cells, endothelial cells, and platelet activation, suggesting a key role in maintenance of the MSIR. ${ }^{74}$ STBEVs have been identified in maternal circulation in the first trimester of normal pregnancy and also found to be significantly elevated in early-onset PE. ${ }^{75}$ Moreover, it is known that STBEV s contain subpopulations of EVs. ${ }^{16}$ As such, it is difficult to utilize the entire STBEV population as a biomarker of PE solely, as there are a multitude of biological factors associated with each EV subtype.

\section{Lipids}

New developments in lipidomic research have led to the identification of multimarker lipid biomarkers of PE. Lipid biomarkers with a mass:charge ratio $(\mathrm{m} / \mathrm{z})$ of $383,784,796$, 798 , and 920 were able to identify PE with sensitivity of $91 \%$ and specificity of $82 \%$. Lipids with an $\mathrm{m} / \mathrm{z}$ of 383 have been identified as oxidized cholesterol, which has been shown to contribute to vascular atherosclerosis in $\mathrm{PE} .{ }^{76}$ However, lipids with an $\mathrm{m} / \mathrm{z}$ of $784,796,798$, and 920 belong to the glycerophosphocholine-lipid class, which may be elevated in PE pregnancies due to enhanced cellular apoptosis. ${ }^{76}$ Although lipidomics provide a new avenue for the identification of $\mathrm{PE}$ biomarkers, further studies are needed to determine if these markers are specific for PE.

In summary, biomarkers of PE can be described as angiogenic and antiangiogenic factors involved in placental maladaptation, improper spiral-artery remodeling, and immune factors that are synthesized as a result of the predominant $\mathrm{T}_{\mathrm{h}} 1$ immunoshift in PE (Figure 2). The dysregulation of these factors in $\mathrm{PE}$ indicates that they may be involved in the etiopathogenesis of the disorder. However, the upregulation of proangiogenic factors, AFP, and HTRA3 indicates that these factors are consequences of the disorder, rather than the cause. Consolidation of the current state of biomarkers in PE indicates that there is no single biomarker of the disorder that can be objectively utilized as a definitive early biomarker of PE. However, placenta-derived exosomes, a key constituent of STBEVs, may best fit the required biomarker criterion of $\mathrm{PE}$ and provide key evidence supporting the etiology and pathogenesis of the disorder. This review thus aims to evaluate the potential of placentaderived exosomes as biomarkers of PE within the approved US Food and Drug Administration(FDA) biomarker-criterion framework.

\section{Placenta-derived exosomes as potential biomarkers of PE}

Placenta-derived exosomes are synthesized by STB cells via the lysosomal pathway, whereby multivesicular bodies fuse with the cell membrane via exocytosis, resulting in the release of placental exosomes into maternal circulation. During the process of exosome biogenesis, selective packaging of molecules into exosomes occurs within the originating cell. These native molecules contained within the exosome thus consist of genetic and proteomic information that could serve as direct markers of pregnancy-related complications/ placental function. However, the rationale for presenting exosomes as a candidate biomarker of $\mathrm{PE}$ is yet to be evaluated in terms of the FDA-approved biomarker criterion. ${ }^{27}$ In this review, we thus incorporate the FDA-biomarker criterion in evaluating placenta-derived exosomes as biomarkers of PE, whereby placenta-derived exosomes were evaluated in view of the following criteria. Can they be objectively isolated, detected, and quantified from biological fluids? Have they been shown to increase with an increase in gestational age in normal pregnancy? Have they been shown to be significantly altered in PE? Do they contain key molecular markers that can improve biomarker sensitivity and specificity? Can they be used as a biotherapeutic agent to reprogram the dysfunctional placenta? 


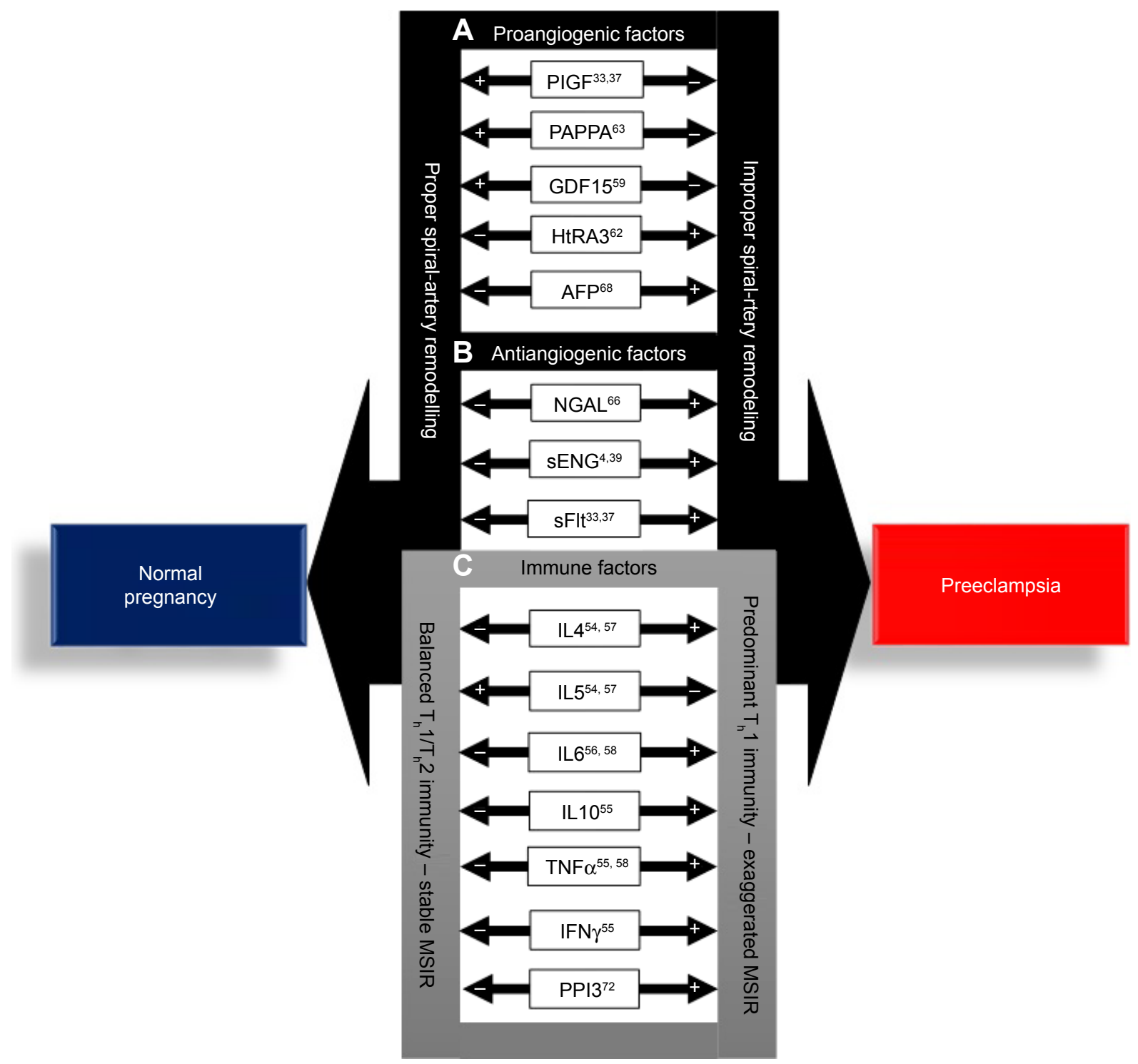

Figure 2 Potential biomarkers involved in the pathogenesis of preeclampsia (PE).

Notes: (A) Proangiogenic and (B) anti-angiogenic factors associated with improper spiral-artery remodeling in PE. (C) Immune factors associated with the pathogenesis of $\mathrm{PE}$ as a result of the predominant $\mathrm{T}_{\mathrm{h}} \mathrm{I}$ immunity of the disorder. ${ }^{+}$Significantly increased expression in comparison to normal pregnancy; ${ }^{-}$significantly lowered expression in comparison to PE pregnancies.

Abbreviations: MSIR, maternal systemic inflammatory response; $T_{h}$, T-helper.

\section{Isolation, detection, and quantification of} placenta-derived exosomes in maternal circulation

Blood is the biofluid of choice when isolating exosomes for research and diagnostic purposes; however, various factors, such as the choice of anticoagulant, venipuncture, blood handling, circadian systems, time of draw, fasting status, platelet activation, and hemolysis, affect the composition and characteristics of exosomes in downstream sample processing and may result in inaccurate results. ${ }^{77}$ It is thus a requirement that when investigating the use of placenta-derived exosomes as biomarkers of PE that standardized blood-collection protocols as recommended by the International Society for Extracellular Vesicles be considered to prevent the artificial release of exosomes, which would result in false positives and negatives. ${ }^{77}$ Exosomes from maternal circulation are generally isolated based on their buoyant density of $1.13-1.19 \mathrm{~g} / \mathrm{mL}$ using density-gradient or static-gradient ultracentrifugation and characterized by microscopic morphology and proteomic identification of exosome-associated tetraspanins, such as CD63, CD9, CD81, and HSP70. ${ }^{78}$ Furthermore, PLAP is used as a placenta-specific marker for the isolation and 
quantification of placenta-derived exosomes. ${ }^{79-81}$ Alternative technologies, such as analytical size-exclusion chromatography and immunoaffinity capture, ${ }^{82,83}$ for the isolation of $\mathrm{PLAP}^{+}$exosomes from maternal circulation have been shown elsewhere; however, these methods, especially the latter, result in analytical challenges with regard to the reproducibility and precision of the quantification of placentaderived exosomes in maternal circulation. Alternatively, the direct quantification of placenta-derived exosomes from total purified exosomes using PLAP as a placenta-specific marker has been achieved. ${ }^{79-85}$ In contrast to immunocapture methods, this method eliminates inaccuracies attributed to the lower exosomal yield obtained using immunocapture techniques. However, the direct quantification of placentaderived exosomes in maternal circulation is largely dependent on the purity of the exosomal fraction. It is thus advisable that density-gradient ultracentrifugation and analytical size-exclusion exosome-isolation methods be utilized in combination to improve the purity and yield of maternal exosomes, thus enhancing the objective identification of placenta-derived exosomes.

The objective isolation of exosomes in maternal circulation coupled with recent advancements in nanotechnology, such as nanoparticle-tracking analysis, enables the accurate characterization and quantification of exosomal populations based on particle-size distribution using dynamic light scattering and Brownian motion. ${ }^{80,85,86}$ Additionally, this technology enables the use of placenta-specific fluorescent probes, such as PLAP and other exosome-specific protein markers, for the quantification of placenta-derived vesicles. ${ }^{86,87}$ With advances in exosome-isolation and -detection technologies, the expected challenges would not only include the discovery of specific PE exosomal markers but also how to incorporate these markers into regulatory decision-making and clinical practice.

\section{Placenta-derived exosomes in normal and complicated pregnancies}

Altered levels of circulating placenta-derived exosomes in PE

Previously, studies have focused on supraphysiological levels of enriched STBEVs in ex vivo systems. ${ }^{12,19,88}$ These studies have demonstrated an increase in STBEVs in ex vivo placental perfusates in PE in comparison to normal pregnancies. Furthermore, it has been established that STBEVs have a key role in immunomodulation during normal and complicated pregnancies, ${ }^{12,83,89}$ and not as purified populations of constituent vesicles, such as exosomes. Exosomes are regarded as a key constituent of STBEVs, due to their ability to reprogram cells and consequently alter normal cellular physiology, which thereby contributes to various pathological states. Although STBEVs in normal pregnancies have been shown to play a role in immunoregulation $^{12}$ and placenta-derived exosomes have been shown to increase with gestational age and alter in vitro endothelial cell migration, ${ }^{80,90}$ there is a lack of knowledge in understanding the role of placenta-derived exosomes in complicated pregnancies, such as those with $\mathrm{PE}$, as well as the relative proportion of these vesicles in relation to other STBEVs.

\section{Role of placenta-derived exosomes in maternal immunomodulation}

Placenta-derived exosomes were initially identified from placental tissue by Frängsmyr et al, and have been shown to contain the transmembrane protein FasL, which suggests that placenta-derived exosomes are involved in immunoregulation during pregnancy by initiating the local deletion of activated maternal lymphocytes that identify placental paternal antigens. ${ }^{91}$ In addition, a similar study by Abrahams et al indicated that exosome-mediated secretion of FasL promotes immunoprivilege of semi-allograph invading trophoblastic cells by inducing apoptosis in Fas-bearing immune cells during implantation and pregnancy. ${ }^{92}$ However, a more recent study showed that $\mathrm{B} 7$ immunomodulatory molecules and HLAG5 are secreted via exosomes from early and term placentas. ${ }^{93}$ This study offered a novel perspective in which human placenta-derived exosomes may have served directly as key mediators of maternal immunotolerance to the semiallogeneic fetus. The identification of these key immunoregulatory proteins bound to placenta-derived exosomes supports the fact that exosomes have an immunomodulatory role in preventing the degradation of invading trophoblastic cells by inducing maternal T-cell apoptosis, which could play a key role in maternal complications, such as PE, fetal rejection, and intrauterine growth restriction.

\section{MSIR and placenta-derived exosomes in maternal circulation}

According to Redman and Sargent, in PE, placental oxidative stress as a result of abnormal placentation induces the release of STBEVs that may control cellular apoptotic and necrotic events in circulation, thus resulting in an exaggerated MSIR. ${ }^{7,15}$ In addition, these authors postulated that in normal pregnancy, the process of regeneration of placental 
STB cells is dependent on cellular apoptosis, which is modulated by STBEVs. ${ }^{7,15}$ In PE, the increase in STBEVs results in an exaggerated MSIR, ${ }^{7,10,86}$ which is induced when the maternal immune system reacts adversely in an exaggerated manner upon exposure to STBEVs. ${ }^{17}$ Since placenta-derived exosomes are a key constituent of STBEVs, we and others ${ }^{16,94}$ thus hypothesize that the marked differences in magnitude of placenta-derived and total exosomes in PE in comparison to normal pregnancies may control $\mathrm{T}_{\mathrm{h}} 1 / \mathrm{T}_{\mathrm{h}} 2$ immunity during pregnancy, which in turn has a direct relationship with the size of the MSIR (Figure 3). In particular, this model proposes that a possible alteration in magnitude of placenta-derived and total exosomes during the pathological progression of early- or late-onset PE may cause adverse conditions or severe complications, which manifest in either severe PE or eclampsia, respectively. Additionally, this hypothesis can be authenticated by the incorporation of a mathematical algorithm whereby the rate of change of placenta-derived exosomes, in relation to total exosomes, within a specified gestational age would enable accurate and reliable diagnosis of PE throughout gestation. This is based on the theory that placenta-derived and total exosomes increase throughout gestation in normal pregnancy, ${ }^{80,81}$ which have been found to be altered in earlyand late-onset PE. ${ }^{85}$ This model represents the classification of early- and late-onset PE based on the ratio of the rate of change of total exosomes to placenta-derived exosomes within a specified gestational age range represented by the following elementary formulae:

$$
\begin{aligned}
\frac{\Delta \mathrm{PLAP}^{+} \text {exosomes }}{\Delta \mathrm{CD}^{+} \text {total exosomes }} & =\frac{\mathrm{PLAP}_{2}^{+}-\mathrm{PLAP}_{1}^{+}}{\mathrm{G}_{2}-\mathrm{G}_{1}} \\
& =\frac{{\mathrm{CD} 63^{+}}_{2}-\mathrm{CD}^{+} 3_{1}^{+}}{\mathrm{G}_{2}-\mathrm{G}_{1}} \\
& =\frac{\mathrm{PLAP}_{2}{ }_{2}-\mathrm{PLAP}_{1}^{+}}{\mathrm{CD}^{+} 3_{2}-\mathrm{CD}_{2}{ }_{1}}
\end{aligned}
$$

where $\mathrm{PLAP}^{+}$exosomes are placenta-derived exosomes, $\mathrm{CD}^{+} 3^{+}$total exosomes, and $\mathrm{G}$ gestational age.

With this hypothetical model, at any specified time period during pregnancy, the calculation of the rate of change in total exosomes to placenta-derived exosomes can be used to assess placental function, impending PE, and the severity of the complication. The model presents the rate of change of $\Delta \mathrm{PLAP}^{+}$exosomes $/ \Delta \mathrm{CD} 63^{+}$exosomes as a relative measure of impending $\mathrm{PE}$ during the preclinical and clinical phases of PE. However, this model is still to be evaluated in a clinical setting, in order to determine the appropriate rate of change for diagnosis/prognosis.

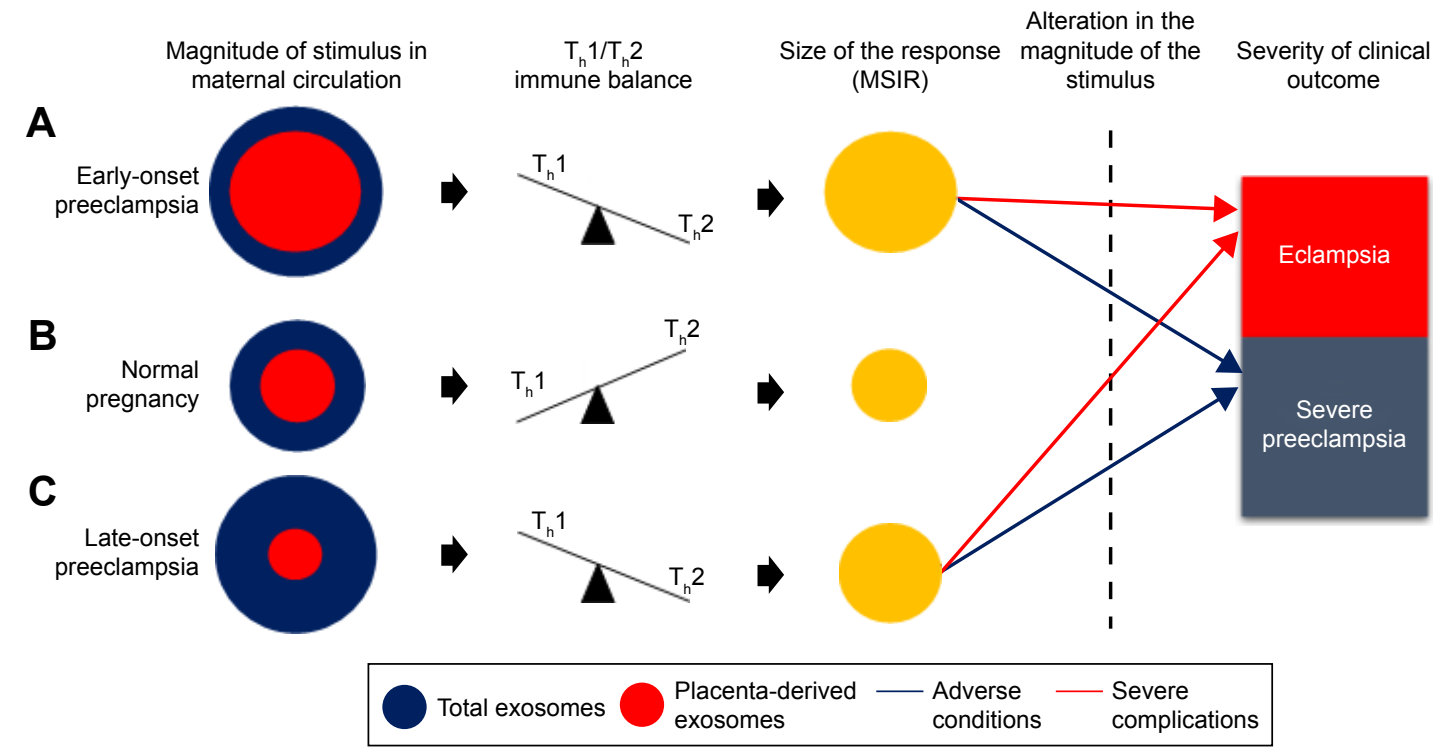

Figure 3 Hypothetical model of exosomes in relation to immunological and clinical outcomes in EOPE, LOPE, and normal pregnancy.

Notes: (A) In EOPE, an increase in placenta-derived and total exosomes in comparison to normal pregnancy mediates a shift toward $T_{h} I$ immunity and thus results in an exaggerated MSIR. (B) In normal pregnancy, there is a balance between placenta-derived and total exosomes that mediates a shift toward $\mathrm{T}_{\mathrm{h}} 2$ immunity, thereby maintaining a balanced MSIR, a requirement for successful pregnancy. (C) In LOPE, the increase in total and decrease in placenta-derived exosomes in comparison to normal pregnancy mediates a shift toward $T_{h} I$ immunity, which exaggerates the MSIR to a degree that does not exceed the MSIR in EOPE. (A, C) Alteration in the magnitude of placentaderived and total-exosomes during the manifestation of LOPE or EOPE results in adverse conditions or severe complications that lead to the clinical manifestation of severe PE or eclampsia.

Abbreviations: EOPE, early-onset preeclampsia; LOPE, late-onset PE; MSIR, maternal systemic inflammatory response; Th, T-helper. 


\section{Molecular markers of placenta-derived exosomes in normal and preeclamptic pregnancies}

Exosomes contain cargo, such as mRNA, miRNA, cytosolic proteins, membrane-bound proteins, and lipids, which are selectively packaged during exosomal biogenesis. Exosomes usually contain a variety of molecules that are native to the originating cell and enriched with endosome-associated protein markers, such as tetraspanins (CD63, CD81, CD82, CD9, CD37), HSP70, RAB proteins, ALIX, TSG101, endocytic proteins, and cell-specific proteins, which provide information regarding their cellular origin. ${ }^{95}$ Pregnancyassociated exosomes have been found to contain a number of membrane-bound protein markers, such as NKGD2 ligands, ${ }^{96}$ FasL, ${ }^{82,83}$ TRAIL, ${ }^{82}$ and syncytin $1,{ }^{97}$ which suggests that placenta-derived exosomes play a key role in maintaining maternal-fetal tolerance (Figure 4). Other specific pregnancy-associated exosomal proteins, such as TGF $\beta$, indicate that placenta-derived exosomes are involved in the control of STB growth, proliferation and differentiation. ${ }^{98}$ Although these exosomal membrane-bound proteins are associated with pregnancy, they cannot be used as definitive markers of placenta-derived exosomes, due to their lack of placental specificity; therefore, placental ALP remains the marker of choice when isolating and identifying placenta-derived exosomes. ${ }^{79-81,85,90,99,100}$ Even though it is known that exosomes contain mRNA and miRNA, which are key molecular mediators in translational and posttranscriptional modification, the exact composition of these exosomal constituents has not been elucidated in placenta-derived exosomes. Therefore, future studies should incorporate identification of novel nucleic acid sequences in placenta-derived exosomes in normal and PE pregnancies to enhance the specificity and sensitivity of these vesicles as biomarkers of PE.

\section{Perspectives on engineered exosomes in PE therapeutics}

Stem cell (SC)-derived exosome therapy is of emerging clinical importance as an alternative to other gene therapies, since exosomes have no risk of aneuploidy and a lower rate of immunorejection following allogeneic administration. ${ }^{101}$ In addition, they serve as ideal vectors for the reprogramming of diseased cells in various pathological states, such as PE, since they have the ability to change the phenotype of the target cell though various signaling cascades and transfer of RNA. ${ }^{102,103}$ Mesenchymal SCs (MSCs) are rich in their application as regenerative agents of damaged or diseased

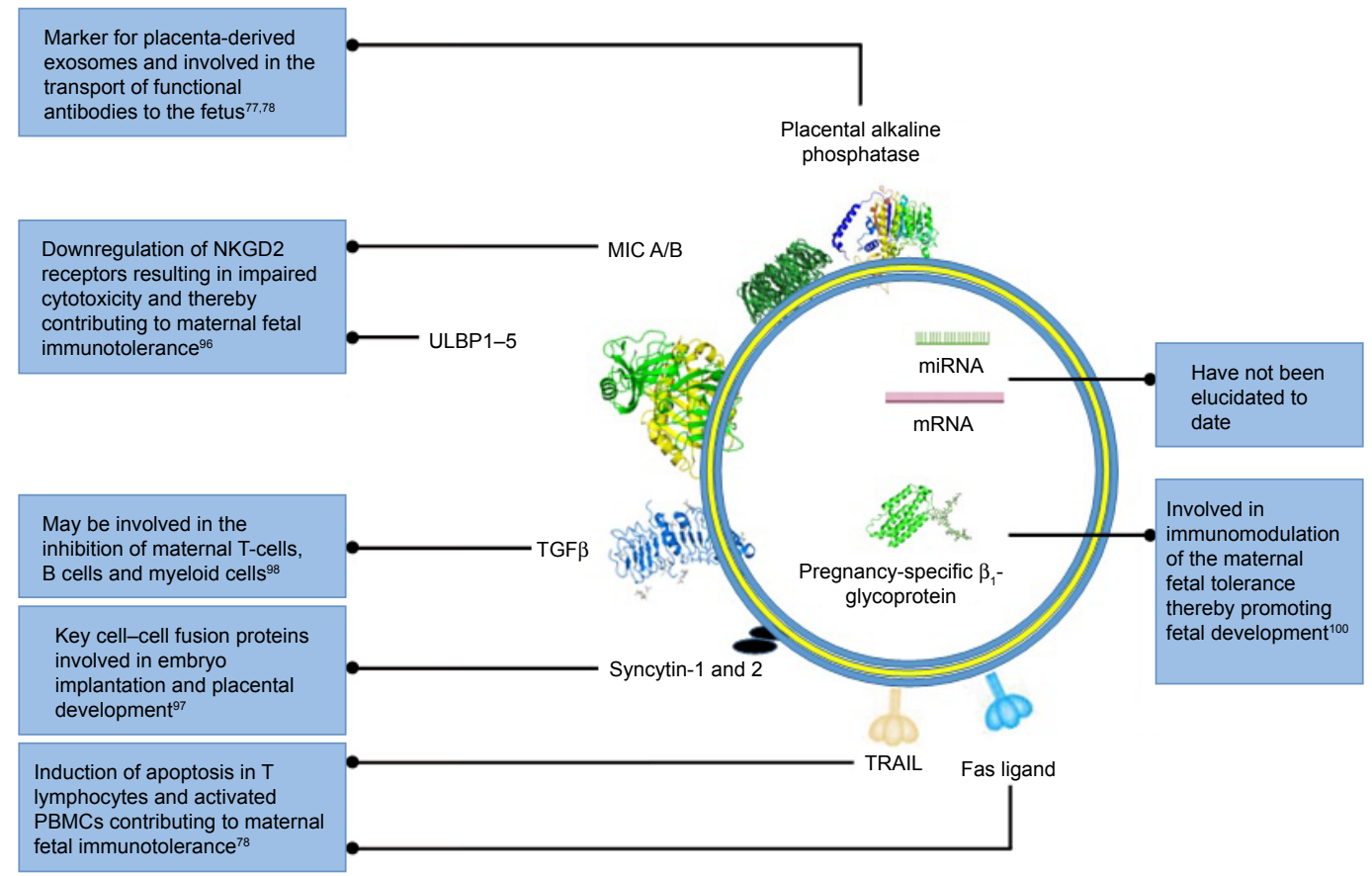

Figure 4 Schematic representation of key pregnancy-associated exosomal molecular cargo and their function.

Notes: This figure highlights key transmembrane and cytosolic proteins involved in immunomodulation during normal pregnancy. Key pregnancy-associated exosomal nucleic acids have not been identified to date. Common exosomal markers are not shown.

Abbreviation: PBMCs, peripheral blood mononuclear cells. 
cells, due to their unique complement of proteins, which promote biological processes and pre-miRNA that facilitate intercellular communication. ${ }^{104-106}$ MSC-derived exosomes have been shown to act as promising therapeutic agents in cardiovascular disease, ${ }^{107,108}$ kidney injury, ${ }^{109}$ immune disease,${ }^{110}$ tumor growth, ${ }^{111}$ and neurological diseases. ${ }^{112,113}$ However the use of MSC-derived exosomes to treat PE has its challenges, due to the complexity of the pathogenesis of the disease. It is thus a prerequisite to determine the role of placenta-derived exosomes in the pathogenesis of PE through isolation and characterization of exosomal cargo and functional activity, and to understand the mechanism of biogenesis of placenta-derived exosomes in normal and PE pregnancies.

Engineering MSC-derived exosomes for the specific treatment of $\mathrm{PE}$ has potential, based on the understanding that exosomes may be primary-role players in the etiopathogenesis of PE. This process would involve the in vitro genetic manipulation of isolated MSCs using plasmid-based vectors to package dsRNA selectively during in vitro MSC-exosome biogenesis to enable the silencing of specific genes involved in the pathogenesis of $\mathrm{PE}$ and to engineer the surface proteins of MSC exosomes to result in their specific delivery to STB cells, allowing for more targeted exosome-cargo delivery. This would enable the effective targeted delivery of RNAi for reprogramming of the diseased placenta.

\section{Conclusion}

The future of the diagnosis of PE is dependent on the identification of novel biomarkers, which in turn may lead to personalized medicine during pregnancy in the form of liquid biopsies. Exosomes are the future of liquid biopsies, as they contain molecular cargo that can be used to diagnose such diseases as cancer without the need for a conventional biopsy. Although there is much controversy regarding the collection, isolation, and characterization of exosomes, the concept of these vesicles as novel biomarkers of the disease remains promising. We project that these shortcomings will be resolved with the implementation of carefully regulated exosomal standardization and validation methods. Additionally, rapid advances in such technologies as nanoparticle-tracking analysis, immunocapture, and next-generation sequencing would improve the efficiency of exosomal isolation and characterization and lead to the identification of novel placenta-derived exosomal protein and nucleic acid markers. The development of algorithms based on the model presented would add value in creating a personalized approach in managing $\mathrm{PE}$ and other pregnancy-related complications. These perspectives form the fundamental basis for the use of placenta-derived exosomes in liquid biopsies of the diseased placenta in PE.

\section{Acknowledgments}

This work was supported by the South African National Research Foundation (grant 107626) and the University of KwaZulu-Natal College of Health Sciences.

\section{Disclosure}

The authors report no conflicts of interests in this work.

\section{References}

1. American College of Obstetricians and Gynecologists. Hypertension in pregnancy. Obstet Gynecol. 2013;122:1122-1131.

2. Kuklina E, Ayala C, Callaghan W. Hypertensive disorders and severe obstetric morbidity in the United States. Obstet Gynecol. 2009;113: 1299-1306.

3. Wagner LK. Diagnosis and management of pre-eclampsia. Am Fam Physician. 2004;70:2317-2324.

4. Redman CW. Current topic: pre-eclampsia and the placenta. Placenta. 1991;12:301-308.

5. Burton GJ, Jauniaux E. Placental oxidative stress: from miscarriage to preeclampsia. J Soc Gynecol Investig. 2004;11:342-352.

6. Knight M, Redman CW, Linton EA, Sargent IL. Shedding of syncytiotrophoblast microvilli into the maternal circulation in pre-eclamptic pregnancies. Br J Obstet Gynaecol. 1998;105:632-640.

7. Redman CW, Sargent IL. Placental debris, oxidative stress and preeclampsia. Placenta. 2000;21:597-602.

8. Redman CW, Sargent IL. Microparticles and immunomodulation in pregnancy and pre-eclampsia. J Reprod Immunol. 2007;76:61-67.

9. Redman CW, Sargent IL. Pre-eclampsia, the placenta and the maternal systemic inflammatory response: a review. Placenta. 2003;24:S21-S27.

10. Sargent IL, Germain SL, Sacks GP, Kumar S, Redman CW. Trophoblast deportation and the maternal inflammatory response in pre-eclampsia. J Reprod Immunol. 2003;59:153-160.

11. Germain SJ, Sacks GP, Sooranna SR, Sargent IL, Redman CW. Systemic inflammatory priming in normal pregnancy and preeclampsia. the role of circulating syncytiotrophoblast microparticles. J Immunol. 2007;178: 5949-5956.

12. Southcombe J, Tannetta D, Redman C, Sargent I. The immunomodulatory role of syncytiotrophoblast microvesicles. PLoS One. 2011;6: e20245.

13. Tannetta D, Masliukaite I, Vatish M, Redman C, Sargent I. Update of syncytiotrophoblast derived extracellular vesicles in normal pregnancy and preeclampsia. J Reprod Immunol. 2017;119:98-106.

14. Tannetta D, Collett G, Vatish M, Redman C, Sargent I. Syncytiotrophoblast extracellular vesicles: circulating biopsies reflecting placental health. Placenta. 2017;52:134-138.

15. Redman CW, Sargent IL. Latest advances in understanding preeclampsia. Placenta. 2005;17:21-27.

16. Redman CW, Sargent IL. Circulating microparticles in normal pregnancy and pre-eclampsia. Placenta. 2008;29:S73-S77.

17. Sargent IL, Borzychowski AM, Redman CW. Immunoregulation in normal pregnancy and pre-eclampsia: an overview. Reprod Biomed Online. 2006;13:680-686.

18. Tannetta DS, Dragovic RA, Gardiner C, Redman CW, Sargent IL. Characterisation of syncytiotrophoblast vesicles in normal pregnancy and pre-eclampsia: expression of Flt-1 and endoglin. PLoS One. 2013;8: e56754.

19. Tannetta DS, Hunt K, Jones CI, et al. Syncytiotrophoblast extracellular vesicles from pre-eclampsia placentas differentially affect platelet function. PLoS One. 2015;10:e142538. 
20. Tranquilli AL, Dekker G, Magee L, et al. The classification, diagnosis and management of the hypertensive disorders of pregnancy: a revised statement from the ISSHP. Pregnancy Hypertens. 2014;4:97-104.

21. Magee LA, Helewa M, Moutquin JM, von Dadelszen P. Diagnosis, evaluation, and management of the hypertensive disorders of pregnancy. J Obstet Gynaecol Can. 2008;30:S1-S48.

22. Huppertz B. Placental origins of preeclampsia: challenging the current hypothesis. Hypertension. 2008;51(4):970-975.

23. Tranquilli AL, Brown MA, Zeeman GG, Dekker G, Sibai BM. The definition of severe and early-onset preeclampsia: statements from the International Society for the Study of Hypertension in Pregnancy (ISSHP). Pregnancy Hypertens. 2013;3:44- 47.

24. Lisonkova S, Joseph KS. Incidence of preeclampsia: risk factors and outcomes associated with early- versus late-onset disease. Am J Obstet Gynecol. 2013;209:544.e1-544.e12.

25. Magee LA, Pels A, Helewa M, Rey E, von Dadelszen P. Diagnosis, evaluation, and management of the hypertensive disorders of pregnancy. Pregnancy Hypertens. 2014;4:105-145.

26. [No authors listed]. Hypertension: management of hypertensive disorders of pregnancy according to international guidelines - a panel discussion (case 5: postpartum eclampsia). Am J Perinatol. Epub 2015 Jun 5.

27. Biomarkers Definitions Working Group. Biomarkers and surrogate endpoints: preferred definitions and conceptual framework. Clin Pharmacol Ther. 2001;69:89-95.

28. Magee LA, Pels A, Helewa M, Rey E, von Dadelszen P. Diagnosis, evaluation, and management of the hypertensive disorders of pregnancy: executive summary. J Obstet Gynaecol Can. 2014;36:416-441.

29. Scazzocchio E, Figueras F, Crispi F, et al. Performance of a firsttrimester screening of preeclampsia in a routine care low-risk setting. Am J Obstet Gynecol. 2013;208:203.e1-203.e10.

30. Park FJ, Leung CH, Poon LC, Williams PF, Rothwell SJ, Hyett JA. Clinical evaluation of a first trimester algorithm predicting the risk of hypertensive disease of pregnancy. Aust N Z J Obstet Gynaecol. 2013; 53:532-539.

31. Poon LC, Kametas NA, Maiz N, Akolekar R, Nicolaides KH. Firsttrimester prediction of hypertensive disorders in pregnancy. Hypertension. 2009;53:812-818.

32. Wang A, Rana S, Karumanchi SA. Preeclampsia: the role of angiogenic factors in its pathogenesis. Physiology (Bethesda). 2009;24:147-158.

33. Maynard SE, Min JY, Merchan J, et al. Excess placental soluble Fmslike tyrosine kinase 1 (sFlt1) may contribute to endothelial dysfunction, hypertension, and proteinuria in preeclampsia. J Clin Invest. 2003;111 649-658.

34. Ahmad S, Ahmed A. Elevated placental soluble vascular endothelial growth factor receptor-1 inhibits angiogenesis in preeclampsia. Circ Res. 2004;95:884-891.

35. Verlohren S, Herraiz I, Lapaire O, et al. The sFlt-1/PlGF ratio in different types of hypertensive pregnancy disorders and its prognostic potential in preeclamptic patients. Am J Obstet Gynecol. 2012;206: 58.e1-e8.

36. Verlohren S, Stepan H, Dechend R. Angiogenic growth factors in the diagnosis and prediction of pre-eclampsia. Clin Sci (Lond). 2012; $112: 43-52$.

37. Stepan H, Herraiz I, Schlembach D, et al. Implementation of the sFlt-1/ PlGF ratio for prediction and diagnosis of pre-eclampsia in singleton pregnancy: implications for clinical practice. Ultrasound Obstet Gynecol. 2015;45:241-246.

38. Verlohren S, Herraiz I, Lapaire O, et al. New gestational phase-specific cutoff values for the use of the soluble Fms-like tyrosine kinase-1/ placental growth factor ratio as a diagnostic test for preeclampsia. Hypertension. 2014;63:346-352.

39. Tsatsaris V, Goffin F, Munaut C, Brichant JF, Pignon MR, Noel A. Overexpression of the soluble vascular endothelial growth factor receptor in preeclamptic patients: pathophysiological consequences. J Clin Endocrinol Metab. 2003;88:5555-5563.

40. Levine RJ, Maynard SE, Qian C, et al. Circulating angiogenic factors and the risk of preeclampsia. $N$ Engl J Med. 2004;350:672-683.
41. Verlohren S, Herraiz I, Lapaire O, et al. The routine measurement of the sFlt1/PlGF ratio allows differential diagnosis of hypertensive pregnancy disorders and has prognostic potential in preeclamptic patients. Pregnancy Hypertens. 2011;1:245-246.

42. Verlohren S, Galindo A, Schlembach D, et al. An automated method for the determination of the sFlt-1/PIGF ratio in the assessment of preeclampsia. Am J Obstet Gynecol. 2010;202:161.e1-161.e11.

43. Robinson CJ, Johnson DD. Soluble endoglin as a second-trimester marker for preeclampsia. Am J Obstet Gynecol. 2007;197:174.e1-e5.

44. Venkatesha S, Toporsian M, Lam C, et al. Soluble endoglin contributes to the pathogenesis of preeclampsia. Nat Med. 2006;12:642-649.

45. Levine RJ, Maynard SE, Qian C, et al. Circulating angiogenic factors and the risk of preeclampsia. $N$ Engl J Med. 2004;350:672-683.

46. Kleinrouweler CE, Wiegerinck MM, Ris-Stalpers C, et al. Accuracy of circulating placental growth factor, vascular endothelial growth factor, soluble Fms-like tyrosine kinase 1 and soluble endoglin in the prediction of pre-eclampsia: a systematic review and meta-analysis. BJOG. 2012;119(7):778-787.

47. Martin A, Krishna I, Badell M, Samuel A. Can the quantity of cell-free fetal DNA predict preeclampsia? A systematic review. Prenat Diagn. 2014;34:686-691.

48. Hahn S, Rusterholz C, Hösli I, Lapaire O. Cell-free nucleic acids as potential markers for preeclampsia. Placenta. 2011;32:S17-S20.

49. Salvianti F, Inversetti A, Smid M, et al. Prospective evaluation of RASSF1A cell-free DNA as a biomarker of pre-eclampsia. Placenta. 2015;36:996-1001.

50. Yu H, Shen Y, Ge Q, et al. Quantification of maternal serum cell-free fetal DNA in early-onset preeclampsia. Int J Mol Sci. 2013;14:7571-7582.

51. Papantoniou N, Bagiokos V, Agiannitopoulos K, Kolialexi A, Destouni A, Tounta G. RASSF1A in maternal plasma as a molecular marker of preeclampsia. Prenat Diagn. 2013;33:682-687.

52. Kolialexi A, Tounta G, Apostolou P, et al. Early non-invasive detection of fetal Y chromosome sequences in maternal plasma using multiplex PCR. Eur J Obstet Gynecol Reprod Biol. 2012;161:34-37.

53. Conka J, Konečná B, Lauková L, Vlková B, Celec P. Fetal DNA does not induce preeclampsia-like symptoms when delivered in late pregnancy in the mouse. Placenta. 2017;52:100-105.

54. Perez-Sepulveda A, Torres MJ, Khoury M, Illanes SE. Innate immune system and preeclampsia. Front Immunol. 2014;5:244.

55. Kumar A, Begum N, Prasad S, Agarwal S, Sharma S. IL-10, TNF- $\alpha$ \& IFN- $\gamma$ : potential early biomarkers for preeclampsia. Cell Immunol. 2013; 283:70-74.

56. Opsjln SL, Wathen NC, Tingulstad S, et al. Tumor necrosis factor, interleukin-1, and interleukin-6 in normal human pregnancy. Am J Obstet Gynecol. 1993;169:397-404.

57. Wegmann TG, Lin H, Guilbert L, Mosmann TR. Bidirectional cytokine interactions in the maternal-fetal relationship: is successful pregnancy a $\mathrm{T}_{\mathrm{H}} 2$ phenomenon? Immunol Today. 1993;14:353-356.

58. Afshari JT, Ghomian N, Shameli A, et al. Determination of interleukin-6 and tumor necrosis factor-alpha concentrations in IranianKhorasanian patients with preeclampsia. BMC Pregnancy Childbirth. 2005;5:14.

59. Chen Q, Wang Y, Zhao M, Hyett J, Costa FS, Nie G. Serum levels of GDF15 are reduced in preeclampsia and the reduction is more profound in late-onset than early-onset cases. Cytokine. 2016;83: 226-230.

60. Nie G, Li Y, Hale K, et al. Serine peptidase HTRA3 is closely associated with human placental development and is elevated in pregnancy serum. Biol Reprod. 2006;74:366-374.

61. Li Y, Puryer M, Lin E, et al. Placental HTRA3 is regulated by oxygen tension and serum levels are altered during early pregnancy in women destined to develop preeclampsia. J Clin Endocrinol Metab. 2011;96: 403-411.

62. Wang Y, Li Y, Hyett J, Costa FS, Nie G. HTRA3 isoform-specific ELISAs for early detection of preeclampsia. J Biomol Screen. Epub 2016 Dec 8.

63. Peterson SE, Simhan HN. First-trimester pregnancy-associated plasma protein A and subsequent abnormalities of fetal growth. Am J Obstet Gynecol. 2008;198:e43-e45. 
64. Lawrence JB, Oxvig C, Overgaard MT, et al. The insulin-like growth factor (IGF)-dependent IGF binding protein-4 protease secreted by human fibroblasts is pregnancy-associated plasma protein-A. Proc Natl Acad Sci U S A. 1999;96:3149-3153.

65. Zwahlen M, Gerber S, Bersinger NA. First trimester markers for preeclampsia: placental vs. non-placental protein serum levels. Gynecol Obstet Invest. 2007;63:15-21.

66. D'Anna R, Baviera G, Giordano D, Todarello G, Corrado F, Buemi M. Second trimester neutrophil gelatinase-associated lipocalin as a potential prediagnostic marker of preeclampsia. Acta Obstet Gynecol Scand. 2008;87:1370-1373.

67. Chakraborty S, Kaur S, Guha S, Batra SK. The multifaceted roles of neutrophil gelatinase associated lipocalin (NGAL) in inflammation and cancer. Biochim Biophys Acta. 2012;1826:129-169.

68. Bredaki FE, Mataliotakis M, Wright A, Wright D, Nicolaides KH. Maternal serum alpha-fetoprotein at 12, 22 and 32 weeks' gestation in screening for pre-eclampsia. Ultrasound Obstet Gynecol. 2016;47: $466-471$.

69. Hawfield A, Freedman BI. Pre-eclampsia: the pivotal role of the placenta in its pathophysiology and markers for early detection. Ther $A d v$ Cardiovasc Dis. 2009;3:65-73.

70. Than NG, Balogh A, Romero R, et al. Placental protein 13 (PP13): a placental immunoregulatory galectin protecting pregnancy. Front Immunol. 2014;5:348.

71. Than NG, Romero R, Kim CJ, McGowen MR, Papp Z, Wildman DE. Galectins: guardians of eutherian pregnancy at the maternal-fetal interface. Trends Endocrinol Metab. 2012;23:23-31.

72. Wortelboer EJ, Koster MP, Cuckle HS, Stoutenbeek PH, Schielen PC, Visser GH. First-trimester placental protein 13 and placental growth factor: markers for identification of women destined to develop earlyonset pre-eclampsia. BJOG. 2010;117:1384-1389.

73. Southcombe J, Tannetta D, Redman C, Sargent I. The immunomodulatory role of syncytiotrophoblast microvesicles. PLoS One. 2011;6: e20245.

74. Lee SM, Romero R, Lee YJ, Park IS, Park CW, Yoon BH. Systemic inflammatory stimulation by microparticles derived from hypoxic trophoblast as a model for inflammatory response in preeclampsia. $\mathrm{Am} \mathrm{J}$ Obstet Gynecol. 2012;207(4):337.e1-e8.

75. Goswami D, Tannetta DS, Magee LA, et al. Excess syncytiotrophoblast microparticle shedding is a feature of early-onset pre-eclampsia, but not normotensive intrauterine growth restriction. Placenta. 2006; 27:56-61.

76. Anand S, Young S, Esplin MS, et al. Detection and confirmation of serum lipid biomarkers for preeclampsia using direct infusion mass spectrometry. J Lipid Res. 2016;57:687-696.

77. Witwer KW, Buzás EI, Bemis LT, et al. Standardization of sample collection, isolation and analysis methods in extracellular vesicle research. J Extracell Vesicles. 2013;2:20360.

78. Théry C, Amigorena S, Raposo G, Clayton A. Isolation and characterization of exosomes from cell culture supernatants and biological fluids. Curr Protoc Cell Biol. 2006;3:1-29.

79. Salomon C, Scholz-Romero K, Sarker S, et al. Gestational diabetes mellitus is associated with changes in the concentration and bioactivity of placenta-derived exosomes in maternal circulation across gestation. Diabetes. 2016;65:598-609.

80. Salomon C, Torres MJ, Kobayashi M, et al. A gestational profile of placental exosomes in maternal plasma and their effects on endothelial cell migration. PLoS One. 2014;9:e98667.

81. Sarker S, Scholz-Romero K, Perez A, et al. Placenta-derived exosomes continuously increase in maternal circulation over the first trimester of pregnancy. J Transl Med. 2014;12:204.

82. Stenqvist AC, Nagaeva O, Baranov V, Mincheva-Nilsson L. Exosomes secreted by human placenta carry functional Fas ligand and TRAIL molecules and convey apoptosis in activated immune cells, suggesting exosome-mediated immune privilege of the fetus. J Immunol.2013;191: $5515-5523$
83. Sabapatha A, Gercel-Taylor C, Taylor DD. Specific isolation of placenta-derived exosomes from the circulation of pregnant women and their immunoregulatory consequences. Am J Reprod Immunol. 2006;56:345-355.

84. Carayon K, Chaoui K, Ronzier E, et al. Proteolipidic composition of exosomes changes during reticulocyte maturation. J Biol Chem. 2011;286:34426-34439.

85. Pillay P, Maharaj N, Moodley J, Mackraj I. Placental exosomes and pre-eclampsia: maternal circulating levels in normal pregnancies and early and late onset pre-eclamptic pregnancies. Placenta. 2016; 46:18-25.

86. Dragovic RA, Collett GP, Hole P, et al. Isolation of syncytiotrophoblast microvesicles and exosomes and their characterisation by multicolour flow cytometry and fluorescence nanoparticle tracking analysis. Methods. 2015;87:64-74.

87. Dragovic RA, Gardiner C, Brooks AS, et al. Sizing and phenotyping of cellular vesicles using nanoparticle tracking analysis. Nanomedicine. 2011;7:780-788.

88. Tannetta DS, Dragovic RA, Gardiner C, Redman CW, Sargent IL. Characterisation of syncytiotrophoblast vesicles in normal pregnancy and pre-eclampsia: expression of Flt-1 and endoglin. PLoS One. 2013;8: e56754.

89. Williams JL, Gatson NN, Smith KM, Almad A, McTigue DM, Whitacre CC. Serum exosomes in pregnancy-associated immune modulation and neuroprotection during CNS autoimmunity. Clin Immunol. 2013;149:236-243.

90. Salomon C, Ryan J, Sobrevia L, et al. Exosome signalling during hypoxia mediates microvascular endothelial cell migration and vasculogenesis. PLoS One. 2013;8:e68451.

91. Frängsmyr L, Baranov V, Nagaeva O, et al. Cytoplasmic microvesicular form of Fas ligand in human early placenta: switching the tissue immune privilege hypothesis from cellular to vesicular level. $\mathrm{Mol}$ Hum Reprod. 2005;11:35-41.

92. Abrahams VM, Straszewski-Chavez SL, Guller S, Mor G. First trimester trophoblast cells secrete Fas ligand which induces immune cell apoptosis. Mol Hum Reprod. 2004;10(1):55-63.

93. Kshirsagar SK, Alam SM, Jasti S, et al. Immunomodulatory molecules are released from the first trimester and term placenta via exosomes. Placenta. 2012;33(12):982-990.

94. Salomon C, Rice GE. Role of exosomes in placental homeostasis and pregnancy disorders. Prog Mol Biol Transl Sci. 2017;145: 163-179.

95. Beach A, Zhang HG, Ratajczak MZ, Kakar SS. Exosomes: an overview of biogenesis, composition and role in ovarian cancer. J Ovarian Res. 2014;7:14.

96. Hedlund M, Stenqvist AC, Nagaeva O, et al. Human placenta expresses and secretes NKG2D ligands via exosomes that down-modulate the cognate receptor expression: evidence for immunosuppressive function. J Immunol. 2009;183:340-351.

97. Vargas A, Zhou S, Ethier-Chiasson M, et al. Syncytin proteins incorporated in placenta exosomes are important for cell uptake and show variation in abundance in serum exosomes from patients with pre-eclampsia. FASEB J. 2014;28:3703-3719.

98. Mincheva-Nilsson L, Baranov V. The role of placental exosomes in reproduction. Am J Reprod Immunol. 2010;63:520-533.

99. Makiya R, Stigbrand T. Placental alkaline phosphatase is related to human IgG internalization in HEp2 cells. Biochem Biophys Res Commun. 1992;182:624-630.

100. Goetzl L, Darbinian N, Goetzl EJ. Novel window on early human neurodevelopment via fetal exosomes in maternal blood. Ann Clin Transl Neurol. 2016;3:381-385.

101. Yu B, Zhang X, Li X. Exosomes derived from mesenchymal stem cells. Int J Mol Sci. 2014;15:4142-4157.

102. Tomasetti M, Lee W, Santarelli L, Neuzil J. Exosome-derived microRNAs in cancer metabolism: possible implications in cancer diagnostics and therapy. Exp Mol Med. 2017;49:e285. 
103. Zhou S, Abdouh M, Arena V, Arena M, Arena GO. Reprogramming malignant cancer cells toward a benign phenotype following exposure to human embryonic stem cell microenvironment. PLoS One. 2017; 12:e0169899.

104. Bruno S, Porta S, Bussolati B. Extracellular vesicles in renal tissue damage and regeneration. Eur J Pharmacol. 2016;790:83-91.

105. Amarnath S, Foley JE, Farthing DE, et al. Bone marrow-derived mesenchymal stromal cells harness purinergenic signaling to tolerize human Th1 cells in vivo. Stem Cells. 2015;33:1200-1212.

106. Lasser C. Exosomes in diagnostic and therapeutic applications: biomarker, vaccine and RNA interference delivery vehicle. Expert Opin Biol Ther. 2015;15:103-117.

107. Suzuki E, Fujita D, Takahashi M, Oba S, Nishimatsu H. Stem cellderived exosomes as a therapeutic tool for cardiovascular disease. World J Stem Cells. 2016;8:297-305.

108. Tsao CR, Liao MF, Wang MH, Cheng CM, Chen CH. Mesenchymal stem cell derived exosomes: a new hope for the treatment of cardiovascular disease? Acta Cardiol Sin. 2014;30:395-400.
109. Suzuki E, Fujita D, Takahashi M, Oba S, Nishimatsu H. Adult stem cells as a tool for kidney regeneration. World J Nephrol. 2016;5:43-52.

110. Tan L, Wu H, Liu Y, Zhao M, Li D, Lu Q. Recent advances of exosomes in immune modulation and autoimmune diseases. Autoimmunity. 2016;49:357-365.

111. Zhang X, Yuan X, Shi H, Wu L, Qian H, Xu W. Exosomes in cancer: small particle, big player. J Hematol Oncol. 2015;8:83.

112. Kalani A, Tyagi N. Exosomes in neurological disease, neuroprotection, repair and therapeutics: problems and perspectives. Neural Regen Res. 2015;10:1565-1567.

113. Xiong Y, Mahmood A, Chopp M. Emerging potential of exosomes for treatment of traumatic brain injury. Neural Regen Res. 2017;12: 19-22.

114. Kolialexi A, Gourgiotis D, Daskalakis G, et al. Validation of serum biomarkers derived from proteomic analysis for the early screening of preeclampsia. Dis Markers. 2015;2015:121848.
International Journal of Nanomedicine

\section{Publish your work in this journal}

The International Journal of Nanomedicine is an international, peerreviewed journal focusing on the application of nanotechnology in diagnostics, therapeutics, and drug delivery systems throughout the biomedical field. This journal is indexed on PubMed Central, MedLine, CAS, SciSearch $®$, Current Contents $\AA /$ Clinical Medicine,

\section{Dovepress}

Journal Citation Reports/Science Edition, EMBase, Scopus and the Elsevier Bibliographic databases. The manuscript management system is completely online and includes a very quick and fair peer-review system, which is all easy to use. Visit http://www.dovepress.com/ testimonials.php to read real quotes from published authors.

Submit your manuscript here: http://www.dovepress.com/international-journal-of-nanomedicine-journal 